\title{
Prenatal exposure to aluminum or stress: I. Birth-related and developmental effects
}

\author{
BRENDA J. ANDERSON, JULIE A. WILLIAMS, SUSAN M. NASH, \\ DAVID S. DUNGAN, and STEPHEN F. DAVIS \\ Emporia State University, Emporia, Kansas
}

\begin{abstract}
Sperm-positive female rats in one of two experimental conditions either ingested aluminum hydroxide (via a Maalox-water mixture) or were stessed (via mild electric shock) during gestation. Birth-related effects, such as stillborn pups, aborted litters, and cannibalism, were found for the animals in the two experimental conditions, but not for the control animals. Significantly lower weights (through 70 days of age) were associated with aluminum-exposed offspring that had been maintained with a nursing mother that had recieved the Maalox-water mixture until weaning.
\end{abstract}

A large amount of animal research concerned with the effects of exposure to a variety of prenatal environments has been conducted. These studies have reported the effects of administering such prenatal insults as malnutrition (e.g., Smart, 1974), ethanol exposure (e.g., Abel, 1978; Abel \& York, 1979; Nash, Weaver, Cowen, Davis, \& Tramill, 1984), and carbon monoxide exposure (e.g., Mactutus \& Fechter, 1984). Without question, such prenatal exposure has produced significant changes and/or effects in the offspring. One of the most frequently reported of these effects has been that of birth-related phenomena. For example, Abel (1978), Martin, Martin, Sigmon, and Radow (1977), and Tze and Lee (1975) have demonstrated that in utero exposure to high doses of ethanol resulted in decreased litter size, decreased size and birth weight of each offspring, and an increased death rate for neonates.

A variety of effects also has resulted from the application of prenatal stress. For example, Miley (1983) reported a reduction in hunger-induced rat-pup killing following prenatal stress. Ward (1972) found that prenatal stress produced a demasculinization and/or feminization of behavior in male rats, which may be attributable to the alteration of the level of fetal and/or maternal androgen during a critical stage of sexual differentiation (Ward, 1974). In support, Moyer, Herrenkohl, \& Jacobowitz (1978) reported that prenatal stress produced changes in catecholamine concentrations in brain regions known to be involved with sexual behavior and gonadotropin secretion. It is interesting to note that the prenatal-stress procedure employed by several of these investigators (e.g., Miley, 1983; Miley, Blustein, \& Kennedy, 1982; Miley, Frank, \& Hoxter, 1981; Ward, 1972) has involved the joint application of whole-body restraint and intense illumination.

Although possible prenatal influences have yet to be

Requests for reprints may be directed to any of the authors, Department of Psychology, Emporia State University, Emporia, KS 66801. reported, it has been shown that aluminum ingestion by adult animals may be involved in the production of some rather dramatic effects. For example, on the basis of findings of elevated aluminum levels in the brain, Crapper and Dalton (1973) and Crapper, Krishnan, and Quittkat (1976) have suggested that Alzheimer's disease may, to some degree, result from and/or be aggravated by ingested aluminum. In support, Perl and Brody (1980) reported finding higher aluminum content in cells having neurofibrillary degeneration. Similarly, Alfrey (1978) and Alfrey, LeGendre, and Kaehny (1976) have found significantly higher aluminum levels in the brain gray matter of the frontal cortex of dialysis encephalopathy victims than in comparable tissue from control subjects. This syndrome has clinical characteristics of cortical speech difficulty such as stammering, hesitancy, and speech arrest, subtle mental and psychiatric changes, abnormal EEG pattern, irregular involuntary muscle contractions typically resulting from a disorder in motor neurons, and dementia (Alfrey, 1978; Alfrey et al., 1976).

The purpose of the present research was to determine what, if any, birth-related and/or developmental effects could be attributed to prenatal exposure to stress or aluminum hydroxide. The stress data described above, in conjunction with data from a pilot study on birth-related effects of prenatal aluminum exposure (Davis, Anderson, \& Dungan, 1984), ${ }^{1}$ suggest the possibility of rather dramatic influences.

\section{METHOD}

\section{Subjects}

Dams. Sixteen sperm-positive female rats were purchased from the Holtzman Company, Madison, Wisconsin. The rats were received on the 2nd day of pregnancy, and upon arrival at the laboratory were placed into individual 10-gal aquariums and maintained on ad-lib food and fluids for the duration of the experiment. Six of the animals were assigned randomly to the aluminum condition, which consisted of exposure to 1:4 mixture of Maalox TC and plain tap water for the duration of gestation. An additional six animals were assigned to the stress condition, which involved a 2 -sec exposure to a .50-mA inescapable footshock twice 
daily for the last 10 days of gestation. The remaining four animals received no prenatal treatment and served as controls.

Offspring. To ascertain the effects of maternal care, one aluminumexposed and one stress-exposed litter were each cross-fostered with a control litter at the time the pups were born. The total number of pups available for study is delineated below.

\section{Procedure}

At birth, all pups were individually weighed, and, if appropriate, litters were cross-fostered. The number of pups, any noticeable birth defects, and the number of stillborn animals, if any, were recorded for each litter. Subsequently, the animals in each litter were weighed on an individual basis every 3 rd day until 70 days of age.

\section{RESULTS AND DISCUSSION}

The first noticeable effect was the occurrence of two apparently aborted litters ${ }^{1}$ : one aluminum exposed and one stress exposed. Furthermore, one complete litter $(n=5)$ of stress-exposed pups was stillborn, and another litter contained four stillborn pups. Within 2 days, the remaining 10 animals in this second litter had succumbed. Although no stillborn fetuses were present, all of the pups from yet another stress-exposed litter had died within 2 days after birth. Cannibalism was noted in both of these latter two stress-exposed litters. Hence, the viable offspring consisted of: (1) three litters of stress-exposed animals $(\mathrm{N}=30)$, one of which was cross-fostered; (2) five litters of aluminum-exposed animals $(\mathrm{N}=56)$, one of which was cross-fostered; and (3) four litters of control animals $(\mathrm{N}=43)$, two of which were crossfostered. It should be noted that the mothers of the four non-cross-fostered Maalox litters were maintained on the Maalox-water mixture until their pups were weaned at 21 days of age.

Mean weight by respective group is shown in Table 1 . As can be seen from Table 1, the animals receiving prenatal exposure to aluminum via the Maalox-water mixture weighed less at birth and, if allowed to remain with a nursing dam who ingested this mixture until weaning, showed a pronounced weight deficit until the weighings were discontinued at 70 days of age.

Analysis of variance performed on the birth weights yielded a significant groups effect $[\mathrm{F}(2,126)=4.19$, $\mathrm{p}<.05]$. Newman-Keuls tests indicated that the Maaloxexposed offspring were significantly $(\mathrm{p}<.05)$ lighter than those of the other two groups, which did not differ reliably from each other. Subsequent ANOVAs, including cross-fostered litters as separate groups, were conducted on the weight data from the following selected days: Days 4, 10, 16, 23, 29, 45, and 70. Because the proportion of males and females within each condition did not differ $\left[\chi^{2}(5)=3.47, \mathrm{p}>.50\right]$, their data were pooled within each group for these subsequent analyses. A significant groups effect was shown on Days 10, 16, 23, 29, 45 , and $70[\operatorname{Fs}(5,123)=4.07,4.13,5.45,3.82,5.36$, 5.61 , respectively, $\mathrm{p}<.01]$. In all instances, subsequent Newman-Keuls tests showed that the Maalox subjects were significantly $(\mathrm{p}<.01)$ lighter than subjects in all other groups, which did not differ reliably. On the other hand, the weight pattern of the cross-fostered aluminum animals indicates that the detrimental growth effects of Maalox ingestion are reversible if they are attended to quickly. Such attention appears to require only the change from the Maalox-water mixture to plain tap water. On the basis of the present data, the critical period for reversing these effects occurs sometime between birth and 21 days of age. One task for future research will be to delineate more closely this critical period via an evaluation of the effects of maintaining nursing dams on the Maaloxwater mixture for different time periods and then evaluating any differential effects in their offspring.

In all fairness, it should be noted that these growthrelated effects may not be attributable to the ingestion of aluminum hydroxide in the Maalox-water mixture. This consideration is prompted by data reported by Thurston, Gilmore, and Swales (1972), who reported similar results from pups given aluminum hydroxide. However, they also found that hyperphosphatemic uremic rats were normal sized. Thus, it seems reasonable to conclude that this growth-related symptom may depend ultimately upon phosphate depletion produced by the aluminum hydroxide ingestion. This consideration, however, does not detract from the main findings of the present study, namely, that (1) prenatal exposure to stress or to aluminum hydroxide via Maalox-water results in aborted litters, stillborn animals, and cannibalism, and (2) continued exposure to aluminum hydroxide until weaning results in significantly lower weights long past the time when the animals are placed on plain tap water.

Table 1

Mean Weight (in Grams) by Treatment Condition at Birth and at Selected Days During Subsequent Development

\begin{tabular}{lccccccccc}
\hline & & & \multicolumn{7}{c}{ Days } \\
\cline { 4 - 9 } & $\mathrm{n}$ & Birth & 4 & 10 & 16 & 23 & 29 & 45 & 70 \\
\hline Aluminum (Maalox) & 44 & 7.13 & 9.63 & 12.95 & 16.56 & 22.63 & 34.38 & 113.00 & 216.55 \\
Cross-Fostered & 12 & & 10.11 & 19.08 & 27.22 & 40.08 & 66.02 & 153.68 & 285.78 \\
Control & 22 & 7.84 & 14.14 & 23.58 & 34.38 & 48.03 & 64.74 & 161.77 & 297.44 \\
Cross-Fostered & 21 & & 12.02 & 22.66 & 28.45 & 45.59 & 65.91 & 158.07 & 300.63 \\
Stress & 18 & 7.93 & 12.32 & 21.64 & 32.34 & 51.91 & 71.77 & 162.45 & 279.83 \\
Cross-Fostered & 12 & & 10.43 & 18.62 & 29.00 & 40.18 & 55.73 & 151.37 & 282.13 \\
\hline
\end{tabular}




\section{REFERENCES}

ABEL, E. L. (1978). Effects of ethanol on pregnant rats and their offspring. Psychopharmacology, 57, 5-11.

ABEL, E. L., \& YoRK, J. L. (1979). Absence of effect of prenatal alcohol on adult emotionality and ethanol preference. Journal of Studies on Alcohol, 40, 547-553.

Alfrey, A. C. (1978). Dialysis encephalopathy syndrome. Annual Review of Medicine, 29, 93-98.

Alfrey, A. C., LeGendre, G. R., \& Kaehny, W. D. (1976). The dialysis encephalopathy syndrome: Possible aluminum intoxication. New England Journal of Medicine, 294, 184-188.

Crapper, D. R., \& Dalton, A. J. (1973). Alterations in short-term retention, conditioned avoidance response acquisition and motivation following aluminum induced neurofibrillary degeneration. Physiology \& Behavior, 10, 925-933.

Crapper, D. R., Krishnan, S. S., \& QuitTKat, S. (1976). Aluminum, neurofibrillary degeneration and Alzheimer's disease. Brain, 99, 67-80.

Davis, S. F., Anderson, B. J., \& Dungan, D. S. (1984, April). The effects of prenatal exposure to Maalox upon gestation and litter size: A preliminary report. Paper presented at the annual meeting of the Southern Society for Philosophy and Psychology, Columbia, SC.

Mactutus, C. F., \& FeChTER, L. D. (1984). Prenatal exposure to carbon monoxide: Learning and memory deficits. Science, 223, 409-411.

Martin, J. C., Martin, D. C., Sigmon, P., \& Radow, B. (1977). Offspring survival, development, and operant performance following maternal ethanol consumption. Developmental Psychobiology, 10, 435-446.

Miley, W. M. (1983). Prenatal stress suppresses hunger-induced ratpup killing in Long-Evans rats. Bulletin of the Psychonomic Society, 21, 495-497.

Miley, W. M., Blustein, J., \& Kennedy, K. (1982). Prenatal stimulation and postnatal testosterone affects infanticide in female rats. Physiology \& Behavior, 28, 627-629.
Miley, W. M., Frank, M., \& Hoxter, A. L. (1981). Rat-pup killing and maternal behavior in male Long-Evans rats: Prenatal stimulation and postnatal testosterone. Bulletin of the Psychonomic Society, 17, 119-122.

Moyer, J. A., Herrenkohl, L. R., \& JAcobowitz, D. M. (1978). Stress during pregnancy: Effect on catecholamines in discrete brain regions of offspring as adults. Brain Research, 144, 173-178.

Nash, S. M., Weaver, M. S., Cowen, C. L., Davis, S. F., \& Tramill, J. L. (1984). Taste preference of the adult rat as a function of prenatal exposure to ethanol. Journal of General Psychology, 110, 129-135.

Perl, D. P., \& Brody, A. R. (1980). Alzheimer's disease: X-ray spectrometric evidence of aluminum accumulation in neurofibrillary tanglebearing neurons. Science, 208, 297-299.

SMART, J. L. (1974). Activity and exploratory behavior of adult offspring of undernourished mother rats. Developmental Psychology, 7, 315-321.

Thurston, H., Gilmore, G. R., \& Swales, J. D. (1972, April 22). Aluminum retention and toxicity in chronic renal failure. Lancet, pp. 881-883.

TzE, W. J., \& LEE, M. (1975). Adverse effects of maternal alcohol consumption in pregnancy and foetal growth. Nature, 257, 479-480.

WARD, I. L. (1972). Prenatal stress feminizes and demasculinizes the behavior of males. Science, 175, 82-84.

WARD, I. L. (1974). Sexual behavior differentiation: Prenatal hormonal and environmental control. In R. Vande Wiele (Ed.), Sex differences in behavior. New York: Wiley.

\section{NOTE}

1. The data from our initial pilot study indicated that $40 \%$ of the Maalox-water exposed dams failed to deliver pups.

(Manuscript received for publication November 8, 1984.) 